\title{
LOGISTICS SUPPORT OF COMPLEX SYSTEMS AND LIFE CYCLE COSTING
}

\section{Bisnoedat Bhola \\ TNO Physics and Electronics Laboratory, NL-The Hague}

Historically, the acquisition of complex systems was focused only on acquisition costs (all costs associated with research \& development, design, construction, production, test and evaluation). Low acquisition costs of systems however have often resulted in high costs for operations and logistics support. This incorporates all tasks to operate the system properly, to keep the system in or to return it to the desired operational state after failures have occurred. These tasks include scenarios for operation, maintenance planning (policies \& levels), personnel, training, documentation, computer resources, facilities, provisioning, spare parts and consumables, ammunition, transport and distribution.

Since 1960 especially in the USA defence community, much effort have been spent to integrate the acquisition, operation and the logistics support to acquire systems with low cost over the total life cycle. This effort resulted in a mangement philosophy called Integrated Logistics Support (ILS) which is based on the incorporation of logistics and operational requirements in the design concept using Logistics Support Analysis (LSA) and Life Cycle Cost Analysis (LCCA).

These concepts have also been studied by TNO Physics and Electronics Laboratory (FEL-TNO) for many years. This article reports the preliminary results of a research project conducted by FEL-TNO for the Ministry of Defence which aims at developing a life cycle cost methodology to integrate the acquisition, operation, logistics support and disposal of complex (military) systems. 